\title{
The Decreasing Significance of Stigma in the Lives of Bisexual Men: Keynote Address, Bisexual Research Convention, London
}

\author{
Matthew Ripley \\ University of Bath \\ Eric Anderson, \\ Winchester University \\ Adrian Adams \\ University of Bath \\ Mark McCormack \\ Brunel University \\ Robin Pitts \\ University of Bath
}

\begin{abstract}
This article is constructed around a keynote address given at the Bisexual Research Convention, held in London, 2010. The keynote was delivered by sociologist Eric Anderson, on behalf of himself and the other authors of this paper. The keynote reflected upon a body of ongoing research, funded by the American Institute of Bisexuality and collected by this team of researchers, into the changing relationship between men and homophobia. It first contextualizes $20^{\text {th }}$ Century attitudes toward homo/bisexuality and, before showing a declining significance of biphobia and homophobia in men's lives today. In accordance with the keynote, this article draws from preliminary findings of multiple ongoing studies of bisexual men in both the United States and the United Kingdom.
\end{abstract}

Keywords: Bisexuality, Masculinities, Homophobia, Sport, Men 


\section{$20^{\text {th }}$ Century Foundations of Homo/Biphobia}

Although homosexuality had not previously been understood as a static sexual identity, this notion came to public consciousness with the conviction of English author, poet, and playwright, Oscar Wilde in 1895. His conviction, profoundly important toward our understanding of sexuality in the 20thCentury, event gave male homosexuals both a spokesperson and a flamboyant stereotype. Femphobia combined with homophobia, to make the $20^{\text {th }}$ Century extremely hostile for sexual minorities.

Research has documented that bisexual men experience stigmatization, discrimination and social exclusion in a range of settings (Barrios, Corbitt, Estes \& Topping, 1976; Herek, 2002; Mohr, Israel \& Sedlacek, 2001). This discrimination has been levied at bisexual men from both heterosexuals and homosexuals (Ochs, 1996). Of particular concern is the erasure of bisexuality as an identity: men who are attracted to both sexes are often regarded as being on the down low, heteroflexible or simply curious (c.f. Denizet-Lewis, 2003; King, 2004). Furthermore, bisexuals are often described as existing within a transitional phase from heterosexuality towards homosexuality (Klein, F. 1993). This belief is even located within academic literature, which frequently favors self-identification over one’s sexual predisposition (c.f. Einberg, 2000). ]

Much of the anti-bisexual attitudes of western culture is linked with homophobia.

Accordingly, while the history of homosexuality is not the same as the history of bisexuality, the two are heavily entwined. Events of the $20^{\text {th }}$ Century socialized homo/biphobia into men; in a way that we show does not occur today.

In the early 1800's, three quarters of people worked in agriculture, a livelihood that brought insecure income. But by the turn of the $20^{\text {th }}$ Century, with its allure of stable wages and the possibility of class mobility that meant that three quarters of the population was now living 
within cities (Cancian 1987). This period of time had substantial impact on $20^{\text {th }}$ Century understandings of homo/bisexuality, and the ‘construction’ of heterosexuality.

In agrarian society, both men and women worked in physically demanding conditions. However as families relocated to cities, and fathers took industrial jobs (leaving their wives at home) women became more domesticated; fulfilling roles that were unseen, unpaid, and for the most part, much less physically demanding than they had worked on the farm (Hartman, 1976). Men on the other hand continued to toil and sweat for their family's income, working in factories and coal mines and other dangerous occupations. These working conditions demanded tough, stoic, and risk-taking men. And, because labor laws had yet to set maximum hours of work, men worked long hours away from their children. Accordingly, they were mostly absent to socialize their sons’ into orthodox notions of masculinity.

With mom at home and female teachers at school, women served as the primary caregivers in young boys lives. It was therefore 'concerning' that young boys were being deprived of the masculine vapors supposedly required to masculinize them. Rotundo (1994: 31) writes, "Motherhood was advancing, fatherhood was in retreat...women were teaching boys how to be men.” Messner (1992: 14) adds, "With no frontier to conquer... and with urban boys being raised and taught by women, it was feared that men were also becoming 'soft,' that society itself was becoming feminized.” In other words, it appeared that the industrial revolution, with its requirement of work away from home, was inadvertently creating soft and feminine boys.

Then, in 1905, with the publication of Sigmund Freud's Three Essays on the Theory of Sexuality, we took on a cultural hysteria about our youth becoming homosexual. Freud's theory suggested that homosexuality was not innate but instead it was something learned during childhood. He believed that the absence of a father figure in a boy's life resulted in what he 
called inversion (homosexuality). This created panic amongst Victorian British and North American cultures. Accordingly, as Oscar Wilde had become the face of the homosexual/invert/sodomite community, his femininity became a symbol of everything to avoid. Masculinity and heterosexuality were now represented by anything that was not homosexual or feminine, and boys suddenly required a masculine figure in their lives-in order to be saved from the perils of inversion.

Alongside the Boy Scouts boys were thrust into sport in a mass political-project aimed at reversing these feminizing trends. Christianity also became highly involved in the project of heterosexualizing male youth. This came through muscular Christianity, a process of using sports to preach the benefits of nationalism, religiosity, and chastity and the sins of homosexuality. Based on patriarchy, homophobia, and misogyny, sport was therefore both deliberate and political in its attempts to create good industrial workers, soldiers, Christians and consumers. This system of creating, what Sedgwick (1990) called 'orthodox’ masculinity remained consistent throughout the $20^{\text {th }}$ century resulting in femininity becoming a sign of weakness—-something men should strive to avoid at all costs.

The most impactful decade for the production of homo/biphobia came in the 1980s. Here, fundamentalist Christianity became a political force, as the so-called 'moral majority' found its voice, and its political leaders in Ronald Regan and Margaret Thatcher. Adding to this, the AIDS crisis demonized homosexuals. And while this led to even higher rates of homophobia than in the 1970s (Anderson, 2009) it had another very influential factor: out of the ashes of AIDS came the the realization that homosexuality existed, not just in a few Oscar Wilde types, but that it existed for millions, in many gendered forms. The presence of same-sex loving men could no longer be denied; they were dying in every social institution. Bisexual men, many even married to women, 
were dying in great numbers.

If there is, however, one benefit to come from the AIDS crisis of the 1980's, it was that gay 'rights' were forced to an even greater public awareness. And, as the virus slowly grew to be associated as a sexually transmitted disease irrespective of sexuality, stigma towards homosexuality began to lessen. Concurrently, public attitudes towards inclusivity gained momentum. Long term social trends reveal that homophobia crested in 1988, held steady for a few years, and then began to decline in 1993 (Loftus, 2001). It has rapidly fallen since (Anderson, 2009). This pattern is mirrored in the UK, although the levels of homophobia in Great Britain have always been markedly better than within the United States (Weeks 2007).

\section{Decreasing Homo/Biphobia}

When it comes to attitudes toward sexual minorities, Western cultures are undergoing rapid change (Anderson 2009; McCormack 2011a; Weeks 2007). The previous decade saw a demise of orthodox views and institutional control of sexual identity, behaviors and relationships (Anderson 2011; Joyner \& Laumann, 2001). This can be highlighted in the vast number of people who engage in pre-marital sexual relations (Johnson et al., 2001) and a continued lessening of the double standards of heterosexual intercourse that now allows women to have increased amounts of casual sex without fear of stigma and social repercussions (Tanenbaum, 1999; Wolf, 1997). University students now engage in frequent casual sex, often called "hooking up” (Bogle, 2008; Stepp, 2007) and most recently, Anderson, Adams and Rivers (2010) have shown that $89 \%$ of white heterosexual undergraduates in the UK have kissed another man.

These changes have had a positive influence on the social and legal environment for gays and lesbians (Loftus 2001; McCormack 2011) as the increased liberal views towards sexual 
conduct has opened up a space in which open and positive discussions about sexual behaviors can occur (Anderson, 2008a; McCormack and Anderson 2010a). With decreasing cultural homophobia, young men in Western cultures are holding more progressive attitudes towards sexuality (Anderson, 2002, 2005; Harris \& Clayton, 2007; McCormack 2010; Pringle \& Markula, 2005; Southall et al 2009), thus providing a cultural space open to a recognition of varying sexualities, and a re-negotiation of the stratification of socially valued and censured sexual behaviors (Rubin 1984).

An example of this can be seen in Anderson's (2008a, 2008b, 2008c) ethnographic studies that focused on what are normally understood to be "bastions of homophobia” (WolfWendel, Toma \& Morphew, 2001), men’s teamsports. Anderson’s body of research (2009) describes how male athletes are becoming increasingly inclined towards emotional and physical (predominantly affectionate rather than sexual) interactions with members of the same sex without feeling social stigma or fear of discrimination. This finding is replicated by Mark McCormack, who found similar results in educational settings in the United Kingdom (McCormack 2010, 2011b; McCormack and Anderson 2010b). This has led to the acceptance of a varying array of sexual behaviors and sexual identities by young men.

If these conservative and traditionally homophobic environments are showing signs of inclusivity, as well as intelligent and mature attitudes to sexuality more generally (attitudes that seem to sometimes mirror queer theoretical perspectives), then there is reason for optimism for increasingly positive experiences of bisexual men. It is possible that the myths concerning bisexuality, and even bisexual discrimination itself, are predominantly the product of a very conservative period of American history-one that our more modern views ameliorate.

Accordingly, this keynote address examined how young men, traditionally known for 
their social conservatism, view bisexuality today. To do this, we combined preliminary and existing findings of six research projects to highlight a more contemporary understanding as to the cultural position of bisexuality, and the levels of biphobia within British and US cultures. Collectively, our research (only some of which is yet published) includes interviews with nearly 100 heterosexual male youths and 90 bisexual men. Together, it explicates the lived experiences of bisexual men, examining for differences across age, race and place.

We conducted semi-structured interviews, alongside participant observation, in order to provide us with a more 'real' understanding as to heterosexual youth's views and beliefs towards bisexualities (Gratton \& Jones, 2004) among male athletes (3 soccer teams in the US; 2 in the UK; and a UK rugby team). Topics included whether participating in same-sex sexual acts necessarily made one gay; whether bisexuality exists as a sexual identity; and how physical and emotional intimacy (as well as sexual desire) were understood in relation to the complexity of sexuality.

Another 90 participants came from openly bisexual males found canvassing the streets of three major western cities (New York $(n=30)$, Los Angeles $(n=30)$ and London $(n=30)$. By calling out to passing crowds that we were researchers looking for bisexual men, we were able to access a cross section of society that included many differing ethnic, religious and racial backgrounds. As well as choosing specific age ranges, we also insisted that these participants had been out for at least a year. This is a notably different sampling group than much research with sexual minority youth (Savin-Williams, 2001). Our discussions focused on the levels of biphobia; their experiences of coming out as bisexual; their relationships with friends, partners and family; and how they felt about the term 'bisexual.' All interviews were recorded, and were erased after interviews were transcribed. Informant's names have been changed to protect 
anonymity. Notes and transcriptions were cross-verified using inter-rated reliability sampling.

In the sections that follow, we highlight some major themes of this research. Rather than presenting results based off of each research setting, we instead summarize results from these multiple, ongoing research projects. Finally, we note that we are grateful to the American Institute of Bisexuality for funding this research.

\section{“Aren't we all a little Bisexual?”}

Throughout our studies we found a prevailing ethos of inclusivity towards sexual minorities. Nowhere was this more startling than our research on heterosexual teamsport athletes. Traditional academic descriptions place sport as being a highly homophobic institution (c.f. Progner, 1990). But these expectations were not matched by our results. The men of the three soccer teams we studied in the US (Anderson, 2009), and two from the UK (Adams, Anderson and McCormack, 2010), as well as a rugby team in the UK (Anderson and McGuire 2010) show that today’s teamsport athletes do not behave in homophobic ways or espousing homophobic attitudes. In fact, just two men from these collective studies expressed homophobic beliefs. These behavioral and attitudinal components of inclusivity were matched by a high number of the men knowing gay men and/or having contact with gay culture. There was ample evidence of pro-gay sentiment in these studies, and an absence of comments or negative reactions about sexual minorities. In fact we find that young men today are quite free to engage in behaviors or activities traditionally coded as 'gay.' This is significant, as young men used to fear association with things socially coded as gay, as it could mean that they were also perceived as gay (Plummer 1999).

It is, however, a fair question to ask as to whether these inclusive views toward 
homosexuality are also an indication of inclusivity toward bisexual men. While we almost always frame our research in terms of 'sexual minorities' it's possible that hegemonic assumptions of what this means determines that it is homosexuals which our participants consider.

There does, however, appear to be a high level of acceptance towards bisexuality. So although bisexuality seems almost non-existent within public discussions, it does appear to be gaining credibility and recognition as a sexual identity in its own right. Of particular interest, few of the heterosexual soccer or ruby players interviewed in these multiple research projects knew bisexual men personally, although the year after interviewing the rugby players a new, openly bisexual, member joined their team. However, their high levels of contact with gay men extended their inclusive sentiment onto bisexual men. Thus, decreased homophobia also seems to lead to decreased biphobia.

\section{Complex understandings of bisexuality}

From the plethora of research that this research team has thus far collected on heterosexual male youth, it appears that most demonstrate complex understands regarding the relationship between sexual orientation, sexual behaviors, and gendered intimacy. For example, in our research on American soccer players, we presented the athletes with questions about the 'one-time rule of homosexuality,' which holds that one same-sex sexual act makes a person gay (Anderson 2008a). But these young men dismissed this rule, suggesting that it was far too simplistic an account of sexuality, and that it was likely based on homophobic attitudes . These men seem capable of intellectualizing a difference between sexual practices and sexual orientation (Adams and Anderson forthcoming); sex with a man does not always equal homosexuality to these men. 
The men in our studies also seem to expand upon the heterosexual/homosexual binary. They do not polarize sexuality as an either/or dichotomy; instead, they articulate their thoughts about sexuality with complexity, often implicating homosocial friendship with love; and thus, homosocial love with sexuality, even in absence of same-sex sexual desire. While most university aged men we interviewed in our various studies reject a binary notion of sexuality, however, few were engaging in same-sex sex.

Alongside recognition of the complexity of bisexuality, there is also a ready acceptance of bisexuality as a legitimate sexual identity (Adams and Anderson, forthcoming). This recognition does not include the traditional stereotypes of indecision, a transitional phase before coming out as gay, or of being 'greedy' simply were not expressed.

Although the men in this study recognized bisexuality as legitimate, only a very small number of participants seem to know bisexual men. While most participants had met or befriended gay men, very few had met bisexual men. This might be interpreted in many ways. Some participants recognized this could be due to their own inability to recognize bisexuals, while others might still lump bisexuals in with homosexuals. This finding is particularly noteworthy, given that many of the participants identified a level of bisexuality in themselves.

This recognition was rarely stated in terms of sexual desire for other men. Instead, it came through the association of homosocial intimacy and love for a friend. Men questioned if love for a woman was part of heterosexuality, if love for a man did not therefore make them somewhat bisexual. This understanding has also improved conditions for openly bisexual men.

\section{An Improved Experience of Bisexual Men across Generations}

Having found inclusive understandings of bisexuality among young heterosexual men, we have 
also been motivated to examine the contemporary experiences of bisexual men of varying age cohorts, in both the UK and the US. However, for this research on 90 men, we sought to avoid studying the same groups of bisexual men that have been studied in the past, which can lead to selection bias (Savin-Williams 2001). Accordingly, we located participants in LA, New York and London by standing on street corners and shouting, 'Bisexual men, we are paying forty dollars [or twenty pounds] for academic research.'

There are several advantages to this method of collecting data. First, because we are interested in the experiences of how bisexual men navigated their sexual identities in public (we were not concerned with internalized homophobia or biphobia), our selection strategy ensured that we interviewed people who welcomed being publicly perceived as bisexual. This method also enabled us to survey a wide range of bisexual men, from three different age groups between 18 and 42. We examined for their experiences of being bisexual in contemporary culture, as well as their own views on a range of issues regarding bisexuality. As suggested earlier, we believe that this decreased biphobia is linked to the decreased cultural homophobia, and sampling different age ranges in different locations allowed us to examine the extent to which this is the case.

Although analysis from this data is ongoing, early findings indicate that young bisexual men have experienced very little homophobia or biphobia directed at them. Older bisexual men have experienced some, but also report this has decreased in recent years. While it is difficult to ascertain the extent to which this is the result of external factors (such as improved attitudes toward bisexuality and a decrease in homophobia) or internal ones (such as improved identity management techniques and selection of friends), this still points to an improved social milieu for bisexual men of all generations. 
Many bisexual men even tell us that they felt confident enough to publicly identify as bisexual at the ages of 13-15. This is not a dominant finding, as around half of the men had still waited until around 18 years of age to come out, but it does highlight bisexual men's growing confidence and the increased social acceptance of bisexuality today. This is supported that we sought only ten interviews of each of three age-groupings in each city. In each case we had to turn down many young bisexuals, before finding enough from the older category to fill our sample: we were not approached by any bisexual men aged over 50 during the entire study.

We also asked bisexual men if the term bisexual works for them and whether they use it. It appears that many of the men do identify as bisexual when asked about their sexuality from strangers, however many intellectualize that the term is far too restricting for them. These individuals suggest that it does not give justice to the complexity of their sexuality. It appears that whilst they are comfortable being called bisexual, and although they use the term themselves, they see limitations in describing themselves as bisexual. Our research has not looked deeply into how these men believe their sexualities could be better described, however initial impressions suggest that perhaps they do not require one: a sense of, “I'm just being me” also emerged in the data. This adds to the growing inclusivity of today's youth and provides reason for optimism for today’s bisexual community.

\section{Conclusion}

The keynote address that Eric Anderson presented at the 2010 Bisexual Research Convention in London, highlighted preliminary results from the multiple and ongoing investigations into bisexuality, today from the five authors of this paper. Although historical events during the turn of the $20^{\text {th }}$ Century left American and British cultures (among other Western countries) with a 
legacy of homo/biphobia and homohysteria; and although social condemnation of same-sex sex between men crested in 1988; matters have been rapidly changing at the turn of the $21^{\text {st }}$ Century.

In our research on six soccer teams, a rugby team, and on street-corner conversations with bisexual men aged 18-42 in London, New York, and Los Angeles, we are finding that, collectively, there is an overt acceptance of homosexuality and bisexuality among heterosexual male youth, and that bisexual men are mostly thriving in their communities. In fact, 48 out of 60 university soccer players (ostensibly heterosexual) in the United States recognized a level of bisexuality within themselves (Adams and Anderson, forthcoming).

The levels of increasing acceptance about sex with men has probably stemmed from a number of cultural influences: a substantial decrease in religious fervor, widened access to the internet; and media exposure (Baunach \& Burgess, 2010). Although very few of the heterosexuals we researched reported direct contact with bisexual men, their decreased levels of homophobia appear to have transferred toward improved attitudes and acceptance of bisexuality. We also found improved experiences of bisexual men. While many of the older men feared identifying as bisexual publicly, because they were, 'too macho' to consider themselves bisexual, the younger participants had more open and inclusive ideas about their own sexual identities and what bisexuality could be.

Data from these ongoing investigations will be published, in the next few years, in a number of academic journals. One is to be published in this journal, The Recognition of Bisexuality in an Unlikely Place, is to appear in the Journal of Bisexuality (Adams and Adnerson) in editors add date and issue number here. Other publications will appear in various journals in forthcoming years. Fortunately, we have recently secured funding from the American Institute of Bisexuality to examine the lived experience of not only 16-18 year old 
bisexual boys in the UK, but we are now in the processes of examining 16-18 year old bisexual girls, too. 


\section{References}

Adams, A \& Anderson, E (forthcoming) “Aren’t we all a little bisexual?” The recognition of bisexuality in an unlikely place. Journal of bisexuality.

Anderson, E. (2002). Openly gay athletes: Contesting hegemonic masculinity in a homophobic environment. Gender \& Society, 16(6), 860-877.

Anderson, E. (2005). Orthodox \& inclusive masculinity: Competing masculinities among heterosexual men in a feminized terrain. Sociological Perspectives, 48(3): 337-355.

Anderson, E. (2005). In the game: Gay athletes and the cult of masculinity. State University of New York Press.

Anderson, E. (2008a). Inclusive masculinities in a fraternal setting. Men and Masculinities, 10(5), 604-620.

Anderson, E. (2008b). "Being masculine is not about who you sleep with...”: Heterosexual athletes contesting masculinity and the one-time rule of homosexuality. Sex Roles, 58, 104-115.

Anderson, E. (2008c). "I used to think women were weak”: Orthodox masculinity, gender segregation, and sport. Sociological Forum, 23(2), 257-280.

Anderson, E. (2009). Inclusive masculinity: The changing nature of masculinities. New York: Routledge.

Anderson, E. (2010). Sport, theory and social problems: A critical introduction. New York: Routledge.

Anderson, E. (2011). The monogamy gap: Men, Cheating and the reality of love. New York: Oxford University press 
Anderson, E., Adams, A. \& Rivers, I. (2010). “You Wouldn’t Believe what Straight Men are Doing with Each Other”: Kissing, Cuddling and Loving. Archives of Sexual Behavior, online first.

Barrios, B. A., Corbitt, L. C., Estes J. P., \& Topping, J. S. (1976). Effect of a social stigma on interpersonal distance. Psychological Record, 26(3), 343-348.

Baunauch, D. \& Burgess, E. (2010). Southern (dis)comfort: Sexual prejudice and contact with gay men and lesbians in the south. Sociological Spectrum, 30, 30-64.

Bogle, K. A. (2008). Hooking up: Sex, dating, and relationships on campus. New York: New York University Press.

Cancian, F. M. (1987). Love in America: Gender and Self-development. Cambridge: Cambridge University Press.

Connell, R.W. (1995). Masculinities. Cambridge: Polity.

Denizet-Lewis, B. (2003, August 3). Double lives on the down low. New York Times Magazine, p.28.

Eigenberg, H. M. (2000). Correctional officers and their perceptions of homosexuality, rape, and prostitution in male prisoners. The Prison Journal, 80(4), 415-433.

Foucault, M. (1984). The history of sexuality, volume 1: An introduction. Translation by Robert Hurley. New York: Vintage.

Freud, S. (1905). Three essays on the theory of sexuality. Complete psychological works (vol. 7). London: Hogarth.

Gratton, C. \& Jones, I. (2004). Research methods for sports studies. Routledge: London. Hartmann, H. (1976). Capatalism, patriarchy and job segregation. Signs Journal of Women in Culture and Society, 1(3), 137-169. 
Herek, G. M. (2002). Psychological heterosexism and anti-gay violence: The social psychology of bigotry and bashing. In M. Kimmel \& M. A. Messner (eds.) Men’s lives (pp. 254-256). Boston, MA: Allyn \& Bacon.

Harris, J., \& Clayton, B. (2007). The first metrosexual rugby star: Rugby union, masculinity, and celebrity in contemporary Wales. Sociology of Sport Journal, 24, 145-164.

Jackson, S., \& Scott, S. (2003). Whatever happened to feminist critiques of monogamy? In H. Graham, A. Kaloski, A. Neilson, \& E. Robertson, (eds.) The feminist seventies. York: Raw Nerve Books.

Johnson, A. C., Mercer, B., Erens, A., Copas, S., McManus, K. \& Wellings, K. (2001). Sexual behaviour in Britain: Partnerships, practices, and HIV risk behaviours. The Lancet, 358(9296): 1835-1842.

Joyner, K. \& Laumann, E. (2001). Teenage sex and the sexual revolution. In E.O. Laumann \& R.T. Michael (eds.), Sex, love, and health in America: Private choices and public consequences. Chicago: University of Chicago Press.

King, J. L. (2004). On the down low: A journey into the lives of "straight" Black men who sleep with men. New York: Broadway Books.

Klein, F. (1993). The bisexual option ( $2^{\text {nd }}$ ed.). Binghamton, NY: The Haworth Press.

Laumann, E. O., Gagnon, J. H., Michael, R. T. \& Michaels, S. (1994). The Social organisation of sexuality: Sexual practices in the United States. Chicago: The University of Chicago Press. 
Loftus, J. (2001). America’s liberalization in attitudes toward homosexuality, 1973 to 1998. American Sociological Review, 66(5), 762-82.

McCormack, M. (2010). The declining significance of homohysteria for male students in three sixth forms in the south of England. British Educational Research Journal, iFirst, 1-17,

McCormack, M. (2011a). Gay friendly high schools: Masculinities, sexualities and friendship. New York: Oxford University Press.

McCormack, M. (2011b). Hierarchy without hegemony: Locating boys in an inclusive masculinity school setting. Sociological Perspectives.

McCormack, M. \& Anderson, E. (2010a). The re-production of homosexually-themed discourse in educationally-based organised sport. Culture, Health \& Sexuality, 12(8), 913-927.

McCormack, M. \& Anderson, E. (2010b). 'It’s just not acceptable anymore:' The erosion of homophobia and the softening of masculinity at an English sixth form. Sociology, 44(5), 843-859.

Messner, M. (1992). Power at play: Sports and the problem of masculinity. Boston: Beacon Press.

Mohr, J. J., Israel, T., \& Sedlacek, W. E. (2001). Councelors’ attitudes regarding bisexuality as predictors of counselors’ clinical responses: An analogue study of a female bisexual client. Journal of Counselling Psychology, 48(2), 212-222.

Ochs, R. (1996). Biphobia: It goes more than two ways. In B. A. Firestein (ed.), Bisexuality: The psychology and politics of an invisible minority (pp. 217-239). Thousand Oaks, CA: Sage.

Plummer, D. (1999). One of the boys: Masculinity, homophobia and modern manhood. New York: Harrington Park Press. 
Pollack, W. (1998). Real boys. New York, NY: Random House.

Pringle, R., \& Markula, P. (2005). No pain is sane after all: A Foucauldian analysis of masculinities and men's experiences in rugby. Sociology of Sport Journal, 22(4), 472497.

Pronger, B. (1990). The arena of masculinity: Sports, homosexuality, and the meaning of sex. New York, NY: St. Martin’s Press.

Rotundo, E.A. (1994). American manhood: Transformations in masculinity from the revolution to the modern era. New York: Basic books.

Rubin, G (1984). Thinking sex: Notes for a radical theory of the politics of sexuality. In Carole S. Vance, C. S (Ed.), p. 275-296. Pleasure and danger: Exploring female sexuality. Boston: Routledge.

Savin Williams, R.C. (2001). A critique of research on sexual-minority youths. Journal of Adolescence, 24(1), 5-13.

Sedgwick, E. K. (1990). Epistemology of the Closet. Berkeley, CA: University of California Press.

Stepp. L.S. (2007). Unhooked: How young men pursue sex, delay love, and lose at both. NewYork, NY: Riverhead Books.

Tanenbaum, L. (1999). Slut: Growing up with a bad reputation. New York: Seven Stories Press. Weeks, J. (2007). The world we have won. New York: Routeledge.

Williams, C. (1993). Doing "women's work": Men in non-traditional occupations. Newbury Park, CA: Sage. 
Wolf, N. (1997). Promiscuities. London: Chatto and Windus. 


\section{Mr. Matt Ripley}

Matt Ripley is an undergraduate in the Department of Education at the University of Bath. He has taken a year out of his studies in order to work on three research projects with Professor Anderson and his team of sexualities researchers. After finishing his BA, he plans on pursuing a PhD with Dr. Anderson.

Email: Mr314@Bath.ac.uk

\section{Professor Eric Anderson}

Eric Anderson is a Professor of Sociology at the University of Winchester. His work examines the changing nature of masculinities in response to decreasing cultural homophobia. Professor Anderson has authored eight books, including The Monogamy Gap: Men, Love, and the Reality $f$ Cheating, with Oxford University Press in 2011.

Email: EricAndersonPhD@aol.com

\section{Mr. Adrian Adams}

Adrian Adams is a PhD candidate in Sociology at the University of Bath. Supervised by Dr. Eric Anderson, he currently has five published articles concerning the intersection of sport, masculinities and sexualities.

Email: Ama20@Bath.ac.uk

\section{Dr. Mark McCormack}

Dr. Mark McCormack finished his PhD in 2010 at the University of Bath. His work examines the intersection of decreasing homophobia and eduaitonal settings. He is the author of a forthcoming 
research monograph with Oxford University Press, Gay Friendly High Schools, and a dozen research articles.

Email: Mark.McCormack@Brunel.ac.u,

\section{Mr. Robin Pitts}

Robin Pitts is completing a Masters in Research at the University of Bath, before pursuing his $\mathrm{PhD}$ with Professor Anderson at the University of Winchester. His interest lie at the intersection gender and sexuality.

Email: Rp342@Bath.ac.uk 